\title{
Spraying n-butyl-2-cyanoacrylate (Histoacryl) might be a simple and final technique for bleeding gastrointestinal lesions
}

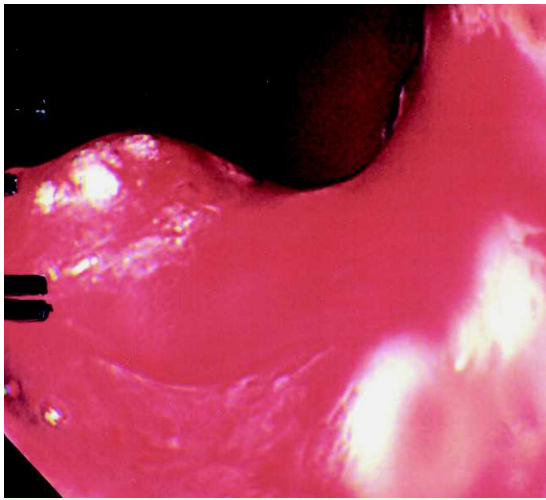

Fig. 1 Pulsatile bleeding due to cancer of the pancreas invading the upper body of the gastric wall.

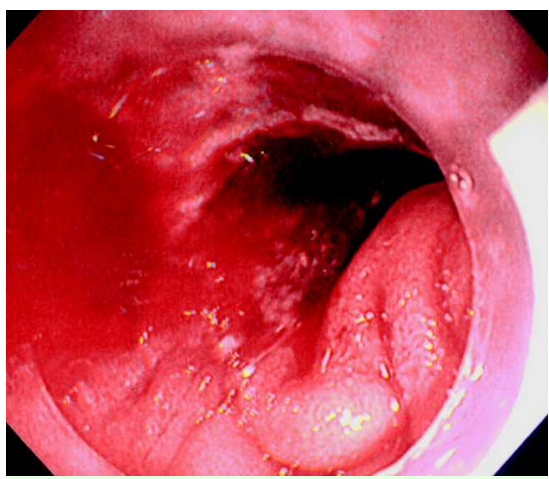

Fig. 2 Heavy oozing due to cancer of the gall bladder invading the first part of duodenum. A clip was applied the day before but hemostasis was unsuccessful.

Histoacryl (n-butyl-2-cyanoacrylate) is widely used for the management of bleeding gastric varices. Histoacryl is usually injected with lipiodol straight into the varices. This method has been shown to be more effective and safer than band ligation [1]. Furthermore, there are some reports that show the efficacy of this method for the management of peptic ulcer hemorrhage when conventional endoscopic hemostatic treatment has failed $[2,3]$. In these reports, Histoacryl is injected directly into the point of bleeding. However, injection of Histoacryl to the vessels may lead to severe complications due to embolization $[4,5]$.

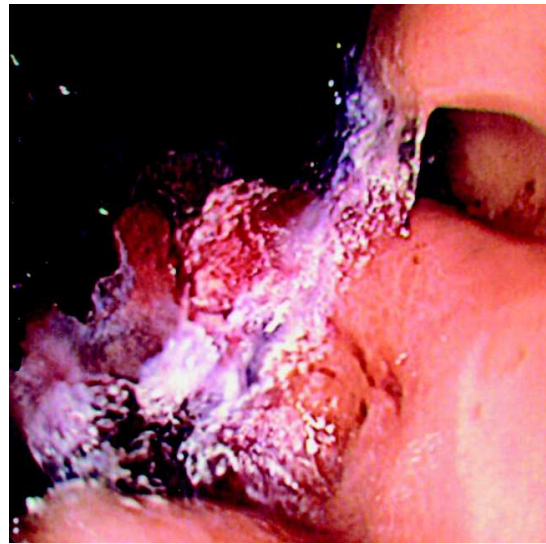

Fig. 3 Bleeding point (from Fig. 1) immediately after spraying Histoacryl. The bleeding point is covered with a crystal-like coating, and hemostasis is completed.

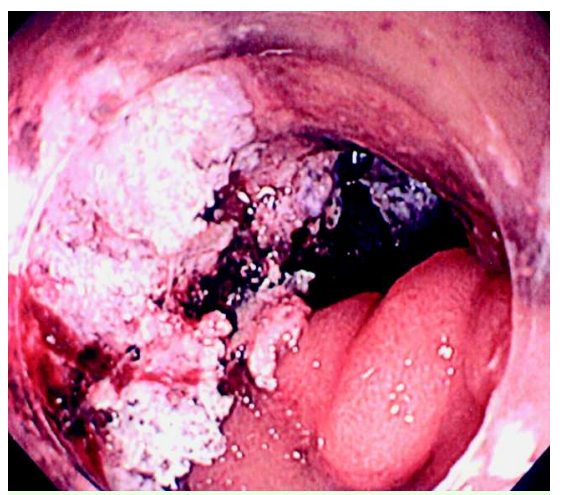

Fig. 4 Bleeding point (from Fig. 2) immediately after spraying Histoacryl.

Here we report a novel method of spraying Histoacryl onto bleeding gastrointestinal lesions in which hemostasis had been difficult to achieve with conventional methods (i.e. clips, coagulation therapies including argon plasma coagulation). Between April 2007 and August 2008, we used this method in four patients in whom conventional endoscopic hemostatic treatment had failed or had seemed difficult. In two of the four patients, who had cancer of the pancreas and gall bladder, respectively, the bleeding was due to tumor invasion into the intestinal wall ( $\odot$ Fig. 1 and Fig. 2). In the remaining two patients, one was bleeding from the

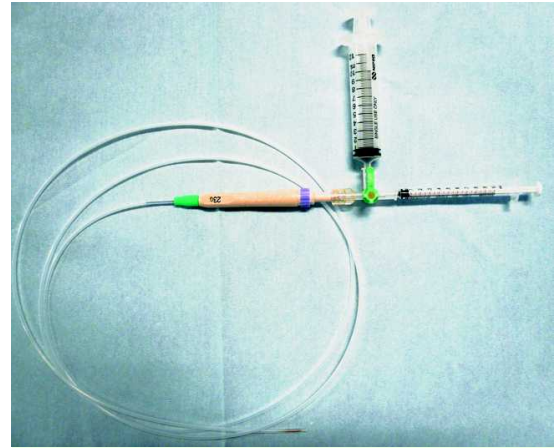

Fig. 5 The set-up for Histoacryl spraying. The 10-mL syringe is used for saline and the 1-mL syringe for Histoacryl. These syringes are connected to the needle ( $23 \mathrm{G}$ ) by a three-way connector.

sigmoid colon following endoscopic mucosal resection and the other from a duodenal ulcer. In all four patients, successful initial hemostasis was achieved.

The knack for this method is to spray (not inject) Histoacryl directly over the bleeding point. Histoacryl will immediately form white crystals when it comes into contact with blood, making a strong seal over the bleeding point ( $\mathrm{Fig.} 3$ and Fig. 4). Usually 1 ampoule $(0.5 \mathrm{~mL})$ is enough to achieve hemostasis. It is also essential to use saline to flush the Histoacryl immediately out of the needle to avoid congelation ( $\odot$ Fig.5). No complication was seen in any of the four patients.

This method is easy to perform and we believe it is much safer than injection. Spraying Histoacryl (n-butyl-2-cyanoacrylate) might be considered when conventional endoscopic hemostatic treatment is unsuccessful.

Endoscopy_UCTN_Code_TTT_1AO_2AD

\section{T. Shida, S. Takano, M. Miyazaki} Department of General Surgery, Chiba University Graduate School of Medicine, Chiba, Japan 


\section{References}

1 Lo GH, Lai KH, Cheng JS et al. A prospective, randomized trial of butyl cyanoacrylate injection versus band ligation in the management of bleeding gastric varices. Hepatology 2001; 33: 1060-1064

2 Lee KJ, Kim JH, Hahm KB et al. Randomized trial of N-butyl-2-cyanoacrylate compared with injection of hypertonic saline-epinephrine in the endoscopic treatment of bleeding peptic ulcers. Endoscopy 2000; 32: $505-511$
3 Kurokouchi K, Maeta T, Ohgi Tet al. Successful treatment of a giant blood vessel in a gastric ulcer by endoscopic sclerotherapy with N-butyl-2-cyanoacrylate. Endoscopy 2007; 38: E250

4 Lee GH, Kim JH, Lee KJ et al. Life-threatening intraabdominal arterial embolization after histoacryl injection for bleeding gastric ulcer. Endoscopy 2000; 32: 422 - 424

5 Cheah WK, So J, Chong SM et al. Duodenal ulcer perforation following cyanoacrylate injection. Endoscopy 2000; 32: S23
Bibliography

DOI $10.1055 / \mathrm{s}-0028-1103472$

Endoscopy 2009; 41: E27-E28

(c) Georg Thieme Verlag KG Stuttgart · New York . ISSN 0013-726X

\section{Corresponding author}

\section{T. Shida, MD, PhD}

Department of General Surgery

Chiba University Graduate School of Medicine 1-8-1 Inohana

Chuo-ku

Chiba 260-8670

Japan

Fax: +81-43-2262552

shidax812@yahoo.co.jp 